\title{
Alzheimer's disease and type 2 diabetes mellitus: similarities in pathomechanisms lead to therapeutic opportunities
}

\author{
Krzysztof Bednarz, Joanna Siuda \\ Department of Neurology, School of Medicine in Katowice, Medical University of Silesia, Katowice, Poland
}

\begin{abstract}
Introduction. Type 2 diabetes mellitus is a metabolic disease the development of which depends on both environmental and genetic factors. The rapid increase in the number of cases observed in recent decades has been associated with the lifestyle predominant in the West, characterised by a high-calorie diet rich in carbohydrates and saturated fatty acids as well as little physical activity and chronic stress. Another disease with growing morbidity is Alzheimer's disease, a neurodegenerative disorder characterised by progressive dementia.
\end{abstract}

State of the art. The results of numerous studies indicate many similarities between these two diseases in terms of their pathomechanisms, especially changes in the activity of enzymatic pathways, accumulation of peptides with altered structure, and chronic inflammation. Amyloid $\beta$, hyperphosphorylated tau protein, amylin, and apolipoprotein $J$ are involved in both pathologies. The reasons for their excessive accumulation are not fully understood, but cellular metabolism disorders associated with insulin resistance and diabetes mellitus may play a key role in this process.

It is highly probable that the changes observed at cellular level, which translate into the clinical state of patients, are caused by many abnormalities common to both diseases.

Clinical implications. The discovery of pathophysiological similarities has resulted in attempts to use antidiabetic drugs in Alzheimer's disease therapy. While animal studies have revealed the potential benefits of oral antidiabetic drugs, studies on humans have not provided clear data regarding their effectiveness. Most clinical trial results are promising, but there have also been studies that have shown no significant, or even adverse, effects of these drugs on Alzheimer's disease course.

Future directions. Undoubtedly, further research is needed to better understand the mechanisms by which the medications used in diabetes treatment affect the nervous system, and further clinical trials to compare the effectiveness of this therapy in patients presenting different clinical conditions at different stages of Alzheimer's disease.

Key words: Alzheimer's disease, type 2 diabetes mellitus, insulin resistance, dementia, antidiabetic drugs

(Neurol Neurochir Pol 2021; 55 (5): 418-428)

\section{Introduction}

Diabetes mellitus is a significant problem for healthcare systems worldwide due to the rapidly growing number of patients diagnosed with this metabolic disease. The estimated number of patients in 1995, approximately 135 million, increased to c. 171 million in 2000 , and 285 million in 2010 . Estimates indicate that by 2030 the number will reach 578 million, and by $2045 \mathrm{c} .700$ million [1]. The more common type is Type $2 \mathrm{di}-$ abetes mellitus (T2DM) occurring in $85-95 \%$ of cases. This is more frequent in middle and older age and strongly associated with excessive amounts of adipose tissue, especially the abdominal obesity that induces increased synthesis of compounds, including inflammatory mediators, contributing to progressive insulin resistance of tissues [2]. Metabolic disorders in T2DM are a complex problem. The disease affects the metabolism of carbohydrates, lipids and proteins, leading to dysfunction of almost all systems and organs of the body including the cardiovascular system, kidneys, eyes, peripheral and central nervous system (CNS) [3]. The influence of factors related to T2DM on the CNS can be observed as atrophic changes in brain tissue in magnetic resonance imaging (MRI) [4].

Address for correspondence: Joanna Siuda, Medical University of Silesia, Katowice, Poland; e-mail: jsiuda@sum.edu.pl

Received: 30.01.2021 Accepted: 24.05.2021 Early publication date: 6.08.2021

This article is available in open access under Creative Common Attribution-Non-Commercial-No Derivatives 4.0 International (CC BY-NC-ND 4.0) license, allowing to download articles and share them with others as long as they credit the authors and the publisher, but without permission to change them in any way or use them commercially. 
Diabetes mellitus increases the risk of various types of dementia, including Alzheimer's disease $(\mathrm{AD})$ and Mild Cognitive Impairment (MCI), by promoting the formation of vascular lesions and ischaemia, altering metabolic processes of neurons and glial cells, and maintaining chronic inflammation. Changes in cognitive abilities can appear at any age and be noticeable even in children with diabetes [4-6]. Untreated or improperly treated diabetes increases the risk of developing dementia and maintaining the physiological level of glycaemia improves cognitive functions, which is why it is so important to restore proper glucose metabolism with appropriately selected pharmacotherapy $[7,8]$.

According to WHO data, various types of dementia affect about 50 million people worldwide. AD is the cause of $50-75 \%$ of dementia cases [7]. There is a rare, early-onset form (age under 65) associated with genes of the amyloid precursor protein (APP) and presenilin 1 and 2 . The most common is the sporadic form occurring in the elderly, the causes of which can be found in environmental and genetic factors such as carrying at least one $\varepsilon 4$ allele of the apolipoprotein E gene (ApoE- $\varepsilon 4)$ [9]. The exact pathomechanism of $\mathrm{AD}$ is unclear. It is known that as a result of excessive accumulation of amyloid beta $(A \beta)$ and hyperphosphorylated tau protein as well as damage to mitochondria, oxidative stress and many other mechanisms, nerve cell death and reduced neurotransmission occur. This leads to increasing cognitive impairment, mood disorders, general disability and, eventually, death [10].

$\mathrm{AD}$ is usually diagnosed based on the patient's medical history, neurological examination and behavioural observations with screening tests, including the commonly used Mini Mental State Examination (MMSE) and the Montreal Cognitive Assessment (MoCA). These scales are useful for the assessment of a patient's cognitive functions and determining whether more detailed evaluation is needed. Recently, in a study which included 281 participants aged over 60 (91 without neurocognitive disorders (NCD) and the other 190 diagnosed with mild NCD), the Polish version of MoCA 7.2 was confirmed to be more sensitive than MMSE in the detection of mild NCD [11]. Structural and functional brain imaging also plays an important role in $\mathrm{AD}$ differential diagnosis. MRI shows atrophy in the cerebral cortex, especially in the medial part of the temporal lobe and the hippocampus. Functional studies with positron emission tomography (PET) detect changes at the early stage of the disease. Neuronal damage in areas such as posterior cingulate gyrus, precuneus, posterior, lateral and medial temporal-parietal association cortex and lateral frontal cortex, are associated with decreased glucose metabolism detected with 18F-fluorodeoxy-glucose (18F-FDG). Other radiotracers that bind to $A \beta$ (florbetapir) or tau protein (flortaucipir) are used in the detection of neurotoxic peptides deposits [12].

As with T2DM, the number of people with $\mathrm{AD}$ will increase due to the ageing population. The common feature of both diseases is treatment based on slowing progression of the disease without being able to stop it completely. Growing knowledge about alterations at the cellular level is revealing more common features in terms of enzymatic pathway insufficiency, chronic inflammation and metabolic disorders [13]. The association between both diseases seems to be particularly strong in the case of carriers of the ApoE- $\varepsilon 4$ allele in whom reduced glucose metabolism was observed in the posterior cingulate, precuneus and lateral parietal cortex $[7,14]$. In addition, carriage of this allele in diabetic patients is associated with increased $A \beta$ accumulation [7].

The many similarities between $\mathrm{AD}$ and $\mathrm{T} 2 \mathrm{DM}$ are why some researchers have dubbed the metabolic disorders underlying the development of AD as 'type 3 diabetes' [8, 13-16].

\section{Common pathophysiological mechanisms underlying T2DM and AD}

\section{Insulin and insulin resistance}

The main feature of T2DM is insulin resistance of tissues leading to impaired glucose transport into cells, changes in intracellular carbohydrates, lipids and protein metabolism, a decrease in glycogen synthesis and an increase in hepatic gluconeogenesis (Fig. 1). A large amount of adipose tissue causes increased production of compounds acting as inflammation mediators, including TNF- $\alpha$ and interleukin- 6 , as well as alterations in the amounts of hormones secreted by adipose tissue, such as leptin and adiponectin. These compounds in physiological concentrations regulate carbohydrates and lipids metabolism and play a significant role in the regulation of satiety and hunger. Besides, these hormones influence the

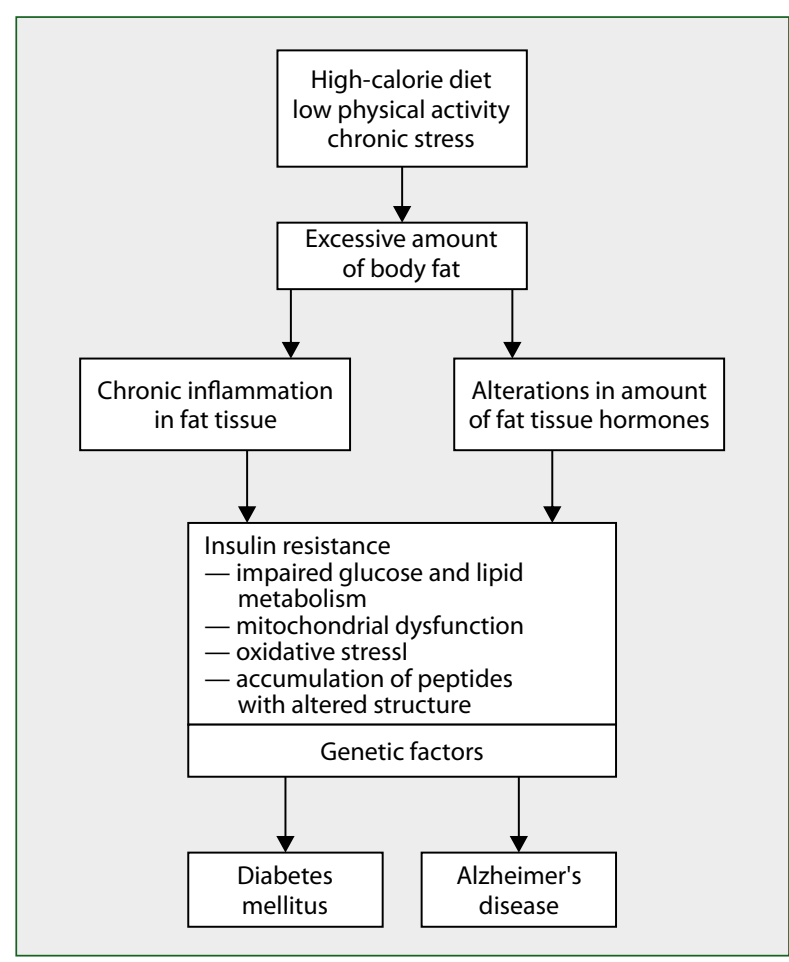

Figure 1. Pathophysiological relations between diabetes mellitus and alzheimer's disease 
CNS. Leptin decreases $A \beta$ deposition by inhibiting $\beta$-secretase and increasing the removal of amyloid deposits from nervous tissue, and also reduces the activity of glycogen synthase kinase 3 (GSK-3 $\beta$ ) associated with excessive tau protein phosphorylation. Adiponectin, the concentration of which is reduced in the case of obesity and diabetes, has the ability to inhibit inflammation [17]. Insulin exerts its effect on cells through the transmembrane insulin receptor (IR) consisting of two a and two $\beta$ subunits [8]. When an insulin molecule binds to one of the $\alpha$-subunits, autophosphorylation of the $\beta$-subunits occurs because of its tyrosine kinase activity. This leads to activation of other enzymes which are part of the signalling pathways. The two most important are the MAPK-related pathway (mitogen-activated protein kinase) and the PI3KAkt-GSK-3 $\beta$ pathway [18-20]. When the balance of cytokines and hormones secretion is disturbed, a detrimental effect on the cells of the liver and other tissues begins to lead to impairment of IR and the associated enzymatic signalling pathways function [13]. Research shows that disorders related to insulin resistance affect not only peripheral tissues but also take place in the central nervous system, and insulin resistance is a phenomenon that occurs in the course of $\mathrm{AD}[21,22]$.

Insulin can cross the blood-brain barrier (BBB). This is evidenced by its presence in the cerebrospinal fluid where insulin concentration increases proportionally to the increase in blood concentration $[8,19]$. Transport of the hormone across the BBB is mediated by receptors on vascular endothelial cells and depends on factors such as inflammation or triglyceride concentration related to obesity [23]. Long-term hyperinsulinaemia, caused by peripheral insulin resistance, also can reduce the transport of insulin across the BBB [24]. Additionally, transport of insulin takes place in structures such as the hypothalamus where the BBB is more permeable. This is confirmed by the increase of insulin activity in these regions after peripheral administration [24,25]. In studies of human and rat brains, the presence of insulin $\mathrm{mRNA}$ has been detected in PCR tests. The presence of C-peptide in human CSF has also been observed, which may indicate a possible central synthesis of this hormone, but these studies require confirmation $[9,19]$. It is also not known how much central insulin synthesis could contribute to the effect of this hormone on nerve cells [26].

In the CNS, insulin performs many important functions, but its role is not as well researched as is its influence on peripheral tissues [18]. There are numerous IRs in the hippocampus and medial temporal cortex which are related to the role of this hormone in memory processes [27]. These receptors are located both presynaptically and postsynaptically and their number, like the concentration of insulin itself, decreases with age [19]. Also, in patients with AD decreased expression of IRs within the CNS has been observed [20,27]. Insulin plays a significant role in creating and strengthening new synaptic connections including the formation of long-term potentiation (LTP). Therefore, it is an important factor in the learning process and impairment of its function in the brain may be one reason behind impaired new memory traces formation in $\mathrm{AD}[8,13]$. Additionally, insulin is related to other cognitive functions including attention and executive functions. It is also one of the factors responsible for regulation of neurotransmitters, such as dopamine, acetylcholine and noradrenaline, by influencing secretion and reuptake $[13,18,19,28]$. It also acts like a growth factor because of its involvement in neurogenesis, nerve cell development and neuroprotection $[7,25]$. Insulin acts on the blood vessels through receptors in endothelial cells and can increase the production of nitric oxide, which causes vasodilatation. In high concentrations, insulin also stimulates the production of endothelin-1, which by constricting blood vessels increases blood pressure, which adversely affects the functioning of many organs including the brain [18]. Insulin resistance of cells or hormone deficiency increases the accumulation of $A \beta$ and the hyperphosphorylated tau protein. Tau protein stabilises the structure of microtubules in neurons, essential for the correct transport of compounds along axons to synapses. This function depends on tau phosphorylation, as the hyperphosphorylated protein does not bind properly with microtubules leading to destabilisation of the cytoskeleton and cell death. Tau protein phosphorylation depends on the activity of kinases including GSK-3 $\beta$. The activity of this enzyme increases due to disruption of the PI3K/Akt signalling pathway when IR stimulation is reduced. High GSK-3 $\beta$ activity leads to a significant increase in tau protein phosphorylation, its function impairment and formation of the neurofibrillary tangles being one of the causes of neuron death in $\mathrm{AD}[7,29]$.

Another important element of insulin's impact on neurons is Insulin Degrading Enzyme (IDE) which is also responsible for the breakdown of other molecules including glucagon, atrial natriuretic peptide, $A \beta$ and amylin [30]. The insulin resistance-induced hyperinsulinaemia in T2DM leads to insufficient enzyme activity against amyloid, due to competition between its substrates, resulting in excessive accumulation of $A \beta$ and damage to nerve cells [31]. Reduction of the Akt activity, caused by decreased stimulation of IRs, can also lead to decreased IDE activity, with all of the consequences mentioned above [32].

On the other hand, it has been observed that $A \beta$ oligomers impair intracellular signalling related to IR, leading to a vicious cycle of increasing insulin resistance and $\mathrm{A} \beta$ accumulation $[7,33]$.

\section{Amylin}

Amylin, also known as islet amyloid polypeptide (IAPP), is produced and secreted with insulin by $\beta$ cells of the pancreatic islets [34]. It plays an important regulatory function by reducing insulin and glucagon secretion, inhibiting gastric emptying and suppressing appetite. Increase in amylin production and accumulation in pancreatic islets, observed in T2DM, leads to $\beta$-cell damage and decrease in insulin production $[35,36]$. Amylin has numerous similarities to $A \beta$ in terms of physicochemical properties such as a similar secondary structure and the mechanism of cytotoxicity $[2,34]$. Both peptides form cell-damaging oligomers and fibrillary deposits which, 
due to their low solubility, cannot be effectively removed from tissues. After penetrating the BBB, amylin can form deposits with $A \beta$ and leads to inflammation, intensification of oxidative stress, mitochondrial dysfunction and nerve cell death [37, 38]. Tissue tests of the pancreas and brain of patients with AD have shown the presence of $A \beta$ and tau protein in pancreatic islet $\beta$ cells in T2DM patients, and even in some non-diabetic patients $[39,40]$. Moreover, it has been shown that amylin can co-deposit with both $A \beta$ and tau protein in the pancreas and CNS. This may indicate that amylin, $A \beta$ and tau are together involved in the development of both T2DM and $\mathrm{AD}$ [41].

Another compound associated with both $\mathrm{AD}$ and T2DM is clusterin (apolipoprotein J). This is a protein involved in the regulation of processes such as cell apoptosis, inflammation and lipid transport $[9,42]$. In view of the fact that the concentration of clusterin in blood is elevated in $\mathrm{AD}$, in pre-diabetes and diabetes mellitus it is possible that clusterin is not only a biomarker but also a factor involved in the course of these diseases [43]. One study showed that the concentration of clusterin correlates negatively with MMSE scores and correlates positively with the concentration of glycosylated haemoglobin (HbA1C), the HOMA-IR index and the concentration of C-peptide. It is also associated with structural changes in the CNS imaging examinations. Clusterin can cross the BBB and is also produced by nerve cells in CNS where it influences the formation of $A \beta$ deposits and its concentration increases with exacerbation of $\mathrm{AD}$ and diabetes [43]. Clearly, the role of clusterin in the course of both diseases requires further research.

\section{Mitochondrial dysfunction, inflammation and oxidative stress}

Dysfunction of mitochondria is an important element of the pathomechanisms of many diseases including T2DM and $\mathrm{AD}[9,44,45]$. The problem is caused by disruption of enzymatic pathways related to the IR and by $A \beta$ accumulation. These phenomena are further intensified by progressive mitochondrial dysfunction which leads to a vicious circle [7]. Impaired function of these organelles results in decreased synthesis of ATP, the main energy carrier in cells, which contributes to cell death [44]. On the other hand, there is increased production of reactive oxygen species (ROS) which are responsible for alterations in the chemical structure of proteins and lipids $[7,46]$. Oxidative stress is especially intense in T2DM because of reduced antioxidant compounds activity. Damage to the mitochondria also leads to disturbances in cellular calcium homeostasis, another factor associated with cell apoptosis $[7,9,47]$.

Chronic inflammation occurs in both $\mathrm{AD}$ and T2DM and leads to IR dysfunction and insulin resistance of tissues. It is associated with increased adipose tissue volume and high concentration of lipid compounds in the blood. Fatty acids can cross the $\mathrm{BBB}$ and are taken up by nerve and glial cells. This process is intensified in people with increased body weight [48]. Saturated fatty acids bind to TLR 4 receptors (toll-like receptor 4) which are associated with the removal of $A \beta$ from the extracellular space in the early stages of $\mathrm{AD}$ [33].

Over time, their activation leads to increased cytokine synthesis in astrocytes and inflammatory response in various structures of the CNS [49]. Chronic activation of microglial cells, associated with the presence of $A \beta$ deposits in the brain tissue, leads to exacerbation of neurodegeneration due to continuous release of inflammatory mediators, including TNF- $\alpha$ and Interleukin-6, as well as neurotoxic ROS by activated glial cells [50]. However, inflammation is associated not only with glial cells. Increased activity of peripheral inflammatory cells in $\mathrm{AD}$ has been observed in the early stages of the disease, and studies indicate an association between the severity of inflammation and cognitive impairment $[51,52]$.

High levels of cytokines in the brain lead to a decreased response of CNS cells to insulin, similarly as in peripheral tissues [37]. Moreover, a high concentration of pro-inflammatory cytokines leads to impaired LTP formation in the dentate gyrus, which results in impaired memory functions [16].

\section{Antidiabetic drugs in AD therapy}

Metabolic disorders, both systemic and directly related to the CNS, lead to progressive loss of nerve cells. This results in impaired functioning of extensive neural networks, largely associated with a significant reduction of neurotransmission. Drugs such as galantamine and rivastigmine inhibit the action of acetylcholinesterase and lead to increased acetylcholine concentration. Memantine exerts neuroprotective activity by NMDA receptor antagonism $[13,53]$. However, this type of therapy is aimed at eliminating the effects of massive neural cell death. On the other hand, attempts to neutralise the causes of neurodegeneration with drugs, such as monoclonal $A \beta$ antibodies (solanezumab, aducanumab, crenezumab) or $\beta$-secretase inhibitors (verubecestat), have not been effective [54-57].

Therefore, it is possible that effective therapy should focus on influencing the metabolic genesis of $\mathrm{AD}$ associated with insulin resistance, inflammation and mitochondrial dysfunction [13]. Connections between $\mathrm{AD}$ and T2DM indicate that drugs used in diabetes therapy may point to a new therapeutic direction in the fight against dementia.

\section{Insulin}

Exogenous insulin is the main agent used in treatment of patients with Type 1 Diabetes Mellitus, and in some situations it is also administered to patients with T2DM. Due to the consequences of insulin deficiency for nerve cells, researchers have drawn attention to the use of insulin in the treatment of AD and MCI.

One study, in which 13 non-diabetic $\mathrm{AD}$ or $\mathrm{MCI}$ patients were administered intranasal insulin for 21 days, showed improvements in memory function and attention compared to a placebo group [58]. Another study with MCI and AD participants showed that short-term (21 days) long-acting insulin administration is more effective with higher doses (40 IU compared to $20 \mathrm{IU}$ ) 
[59]. Moreover, long-term insulin administration (4-month therapy) resulted in improvement of memory functions associated with slowing of atrophic changes in MRI and an improvement in the tau-P181/ A $\beta 42$ ratio, but in this case the effects were noticeable with the use of short-acting insulin [60]. A recent study, in which patients with MCI or AD were administered insulin in daily doses of 40 IU for 12 months, showed no positive changes in terms of cognitive functions [61]. In clinical trials, insulin is administered intranasally and transport to CNS along the trigeminal nerve and the olfactory tract [62]. This route of administration is intended to minimise the risk of systemic side effects, such as hypoglycaemia, that could be the result of peripheral injections.

Moreover, the nasal route of administration is associated with more effective delivery of appropriate doses to the CNS $[62,63]$. Insulin has an effect on tau protein phosphorylation and A $\beta$ removal as well as APP metabolism, and by these effects is probably responsible for a positive impact on the $\mathrm{AD}$ patients who take it [64]. A positive response to insulin therapy, in terms of improving cognitive abilities in these patients, is gender-related, with males responding better to higher doses (40 IU) than females [65]. The result seems to be influenced also by the carriage of the ApoE- $\varepsilon 4$ allele. At high insulin doses, ApoE- $\varepsilon 4(-)$ males achieved a better response to treatment than APOE- $\varepsilon 4(+)$. The opposite effect was observed in high-dose group females. ApoE $\varepsilon 4$ (-) females had the worst cognitive performance while ApoE $\varepsilon 4(+)$ remained stable. ApoE $\varepsilon 4(+)$ males and females with high insulin dose obtained results without significant improvements or decreases [65]. These differences could be a result of interaction of ApoE4 with the IR, observed in mice, causing the impairment of IR transport to the cell membrane by trapping it in endosomes which results in decreased insulin response in ApoE- $\varepsilon 4$ allele carriers [66].

\section{Metformin}

Metformin is the first-line medication in T2DM therapy [19]. It is orally administered and has the ability to penetrate to the brain tissue across the BBB [67]. The mechanism of its action is based on increasing cells sensitivity to insulin. A significantly reduced risk of dementia has been reported in metformin users [68]. Observations of diabetic patients taking metformin show a positive effect of this drug on cognitive functions [64]. Clinical trials have confirmed the safety of metformin and its penetration into the CNS as well as the association with improvements in executive functions, memory and attention in patients with $\mathrm{MCI}$ and $\mathrm{AD}$ [58]. An improvement in the ADAS-Cog (Alzheimer's Disease Assessment Scale-Cognitive subscale) score, which measures cognitive abilities, was also observed in patients with MCI who were overweight or obese, but not diabetic [69]. Another study showed that only participants taking metformin in monotherapy achieved significant improvements in cognitive function measured by neuropsychological tests [70].

However, there is some evidence that metformin may also cause cognitive decline, and that prolonged use could even increase the risk of $\mathrm{AD}[71,72]$. Certainly, further studies are needed to find the cause of these contradictions in the results of previous research and to set optimal doses and durations of therapy as well as to identify patients who could achieve significant benefits from metformin therapy. The MAP study (Metformin in Alzheimer's Dementia Prevention, ClinicalTrials.gov Identifier: NCT04098666) was planned to start in early 2021. This is a multicentre, randomised, phase II / III study in 370 male and female participants with early-stage MCI and without diabetes. The study will provide new data about the role of metformin in inhibiting the progression of dementia.

\section{Liraglutide}

Liraglutide is an antidiabetic drug from the group of GLP-1 analogues (Glucagon-like peptide-1). In the CNS, receptors for GLP-1 are located in many areas including temporal cortex and hippocampus [73]. Studies have shown enhanced learning abilities in mice with high expression of GLP-1 receptors within the hippocampus [74]. Liraglutide has a positive effect on CNS glucose transport and metabolism observed with FDG-PET in AD patients [75]. In rodents, the drug increased neurogenesis, had a neuroprotective effect by reducing the amount of $A \beta$ and hyperphosphorylated tau reducing inflammation, and also had a positive effect on memory by participating in LTP formation [76-79]. Studies on a mouse model of AD have shown that liraglutide can improve memory functions and increase the number of nerve cells in the hippocampus [80].

Most of these effects have been observed in studies on animal models, therefore clinical trials in large groups of patients are necessary to assess the long-term efficacy of liraglutide in reducing $\mathrm{AD}$ symptoms. The effect of liraglutide on the human nervous system has already been observed as detected in fMRI improvement of connectivity within the Default Mode Network (DMN) seen after 12 weeks of liraglutide therapy [81]. However, the participants were not diagnosed with dementia and the study found no changes in cognitive function. The influence of liraglutide on the course of $\mathrm{AD}$ was also the subject of the ELAD study (Evaluating the effects of the novel GLP-1 analogue Liraglutide in Alzheimer's Disease) [82]. Its purpose was to evaluate changes in cerebral glucose metabolism in $\mathrm{AD}$ patients after 12 months of daily administration of liraglutide compared to a placebo group. Participants were examined by PET of medial temporal lobe, posterior part of cingulate cortex and hippocampus. Changes in the condition of the study participants were also assessed with scales measuring the severity of AD symptoms (Alzheimer's Disease Assessment Scale, Executive Domain Scores of the Neuropsychological Test Battery, Clinical Dementia Rating Sum of Boxes, and Alzheimer's Disease Cooperative Study - Activities of Daily Living), MRI scans and several other parameters. Unfortunately, during the CTAD (Clinical Trials on Alzheimer's Disease) congress in November 2020, it was reported that no changes in glucose metabolism were observed in studied regions of the brain between the groups administered the drug and the placebo. 
Dipeptidyl peptidase-4 (DPP-4) inhibitors

DPP-4 inhibitors are a class of medications that act on the enzyme responsible for the inactivation of incretin compounds including GLP-1. The inhibition of DPP-4 increases GLP-1 level in the blood, thus enhances not only the antidiabetic properties of incretins but also those associated with a beneficial effect on the CNS.

In animal models of $\mathrm{AD}$, linagliptin, a highly specific and potent inhibitor of DPP-4, improved cognitive function, and decreased inflammatory markers, tau phosphorylation and $\mathrm{A} \beta$ aggregation $[55,83]$. A study of the neuroprotective properties of linagliptin on human nerve cells has shown that the drug can protect neurons from the effects of $A \beta$ on mitochondrial damage, oxidative stress and impairment of IR signalling. Restoring the proper functioning of the IR pathways is caused by inhibition of GSK-3 $\beta$ activity, which leads to a reduction in tau protein phosphorylation [84]. These effects could be useful in AD therapy [55].

Sitagliptin also may improve the condition of patients with AD. In one study, 253 elderly patients with T2DM (205 participants, including 52 with $\mathrm{AD}$, completed the study) were divided into a sitagliptin and a non-drug group [85]. After six months of therapy, the group taking the drug not only required lower doses of insulin (improved glycaemic control in diabetes) but also achieved better MMSE scores. Improvement was seen in both $\mathrm{AD}$ patients and those without dementia.

\section{Thiazolidinediones}

This is a class of antidiabetic agents which act by peroxisome proliferator-activated receptors (PPAR- $\gamma$ ) and result in increased insulin sensitivity of tissues. These drugs not only normalise blood glucose level, but also have a positive effect on the lipid profile, which is very beneficial for patients with T2DM [86]. Pioglitazone, in addition to the above-mentioned effects, also has many properties that could be helpful in the treatment of $\mathrm{AD}$ [87]. This drug has the ability to reduce the amount of $A \beta$ deposits. In vitro studies on rat nerve cells have shown that pioglitazone can inhibit the phosphorylation of the PPAR- $\gamma$ which regulates the expression of IDE, an enzyme responsible for $A \beta$ degradation. PPAR- $\gamma$ also influences expression of $\beta$-secretase involved in APP processing leading to generation of $A \beta$ [88]. The neuroprotective role of pioglitazone could also be related to a decrease in TNF- $\alpha$ concentration [89]. In mice treated for two weeks with pioglitazone and leptin, a positive effect of this form of therapy on spatial memory and on the amount of $A \beta$ deposits was observed [90]. In healthy, elderly patients treated with low doses of pioglitazone $(0.6 \mathrm{mg})$ for two weeks, an increase in fMRI-measured hippocampal cells activity was observed during tasks involving memory functions [91]. Subsequent studies have shown an improvement in cognitive functions after pioglitazone therapy in patients with T2DM as well as MCI and $\mathrm{AD}$, as well as an increase in cerebral blood flow within the parietal lobe in patients with T2DM and AD $[92,93]$.
Rosiglitazone improves spatial memory tested in the Morris water maze and increases removal of $A \beta$ deposits, similarly to pioglitazone, by increasing IDE expression in diabetic and AD-induced mice [94]. The positive effect of rosiglitazone on nerve cells and formation of LTP in the dentate gyrus of rodents can also be a consequence of drug-associated decreased production of proinflammatory cytokines including IL-1 $\beta$ and IFN $\gamma$ [95]. There are many conflicting results from clinical trials regarding the efficacy of rosiglitazone in dementia treatment. Some trials indicate that the drug may improve cognitive performance in patients with $\mathrm{MCI}$ and $\mathrm{AD}$ [96]. However, later studies do not confirm such an effect [97].

\section{Drugs affecting amylin receptors}

Pramlintide is a synthetic amylin analogue for use in the treatment of Types 1 and 2 Diabetes Mellitus. It works by slowing gastric emptying and reducing glucagon secretion which results in improved glycaemic control [38]. It does not show the ability to form deposits which in the case of amylin impair physiological functions [98]. In studies on animal models, it has been observed that administration of amylin or pramlintide reduces the amount of $A \beta$ deposits and phosphorylated tau protein, decreases inflammation, and improves cognitive functions $[38,99]$.

Amylin receptor antagonists act by blocking amylin receptor (AMYR). Substances such as AC253 weaken the harmful effects of amylin and $A \beta$ oligomers on cells via these receptors [38]. Injection of AC253 into the brain ventricles improves spatial memory and decreases microglia activity. It has been observed that the cyclic form of AC253 has better stability, better accessibility to brain tissue, and higher affinity for AMYR than the original form of AC253 [100]. Interestingly, pramlintide and AMYR antagonists have a similar effect on the nervous system, although their actions on AMYR are in opposite directions [38].

As can be seen, the results of clinical trials do not provide a clear answer to the question of therapeutic effectiveness in AD. Some conflicting conclusions drawn from these studies may be related to the high heterogeneity of participants. Patients at different stages of disease can react differently to the same treatment. It is also important to stress that we still do not know all of the pathophysiological mechanisms of both metabolic and neurodegenerative disorders, so we cannot comprehend all the variables that could potentially affect the treatment outcomes in patients with apparently similar clinical conditions.

\section{Conclusions and future directions}

T2DM and AD present major challenges to healthcare systems. This challenge will continue to grow due to increases in the main risk factors for both diseases observed in the population. Despite the differences in clinical presentation, diabetes and $\mathrm{AD}$ appear to have many similarities in terms of metabolic alterations in cells. Some studies show a positive effect of antidiabetic drugs in improving cognitive function in people with dementia, although some results have been less positive (Tab. 1). 


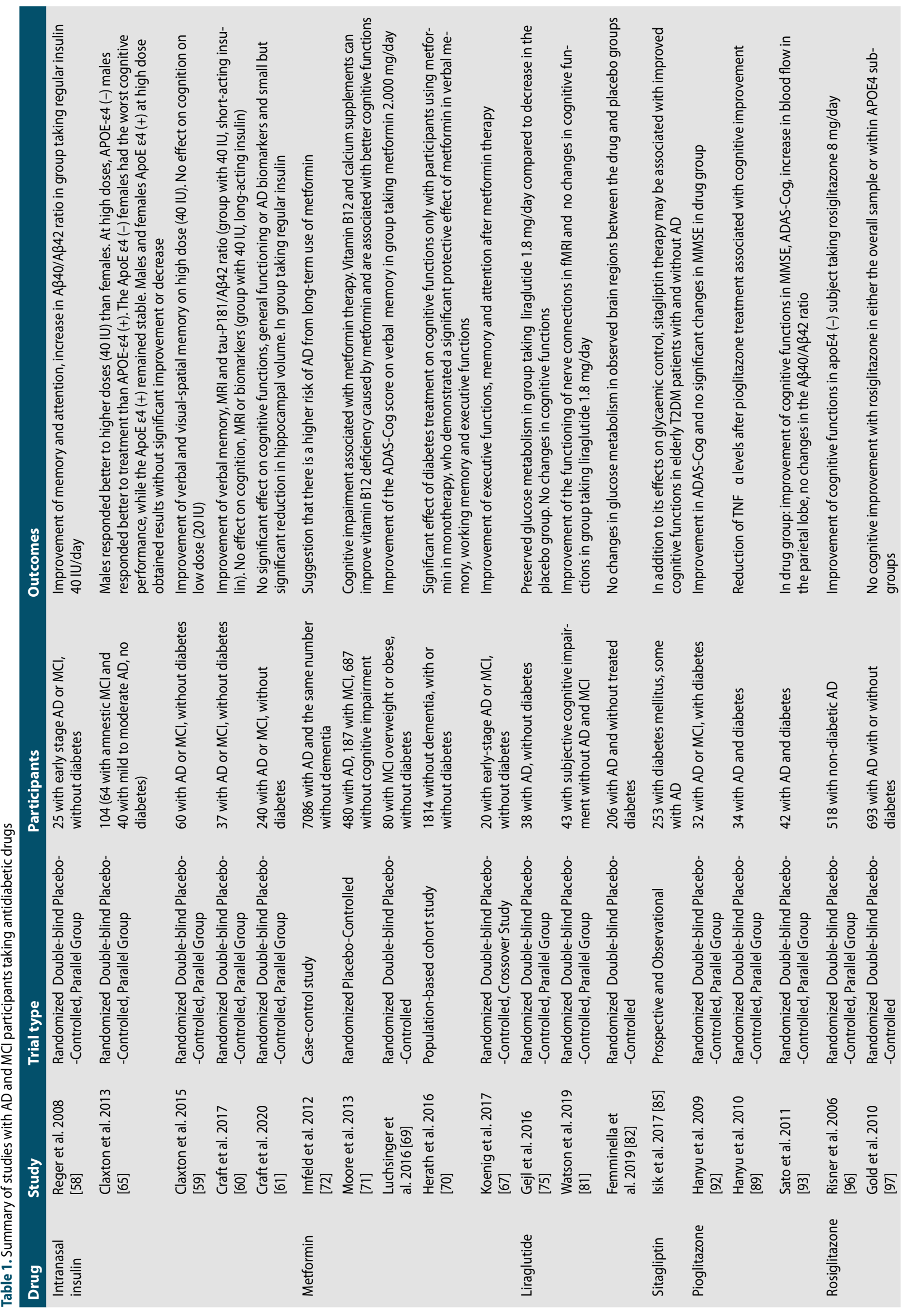


Clearly, further research and observations are needed. This seems to be promising area to investigate, and the amount of medications used in the therapy of diabetes that could affect the condition of dementia patients is considerable.

The future will reveal whether the knowledge obtained through laboratory studies and clinical trials will result in improvements in the condition of patients.

Funding: None.

Conflicts of interest: None.

\section{References}

1. Saeedi P, Salpea P, Karuranga S, et al. IDF Diabetes Atlas Committee. Global and regional diabetes prevalence estimates for 2019 and projections for 2030 and 2045: Results from the International Diabetes Federation Diabetes Atlas, 9 edition. Diabetes Res Clin Pract. 2019; 157: 107843, doi: 10.1016/j.diabres.2019.107843, indexed in Pubmed: 31518657.

2. Akash MS, Rehman $\mathrm{K}$, Chen $\mathrm{S}$, et al. Role of inflammatory mechanisms in pathogenesis of type 2 diabetes mellitus. J Cell Biochem. 2013; 114(3): 525-531, doi: 10.1002/jcb.24402, indexed in Pubmed: 22991242.

3. Papatheodorou K, Papanas N, Banach M, et al. Complications of Diabetes 2016. J Diabetes Res. 2016; 2016: 6989453, doi: 10.1155/2016/6989453, indexed in Pubmed: 27822482.

4. Biessels GJ, Despa F. Cognitive decline and dementia in diabetes mellitus: mechanisms and clinical implications. Nat Rev Endocrinol. 2018; 14(10): 591-604, doi: 10.1038/s41574-018-0048-7, indexed in Pubmed: 30022099.

5. Rönnemaa E, Zethelius B, Sundelöf J, et al. Impaired insulin secretion increases the risk of Alzheimer disease. Neurology. 2008; 71(14): 1065-1071, doi: 10.1212/01.wnl.0000310646.32212.3a, indexed in Pubmed: 18401020.

6. S Roriz-Filho J, Sá-Roriz TM, Rosset I, et al. (Pre)diabetes, brain aging, and cognition. Biochim Biophys Acta. 2009; 1792(5): 432-443, doi: 10.1016/j.bbadis.2008.12.003, indexed in Pubmed: 19135149.

7. Sun $\mathrm{Y}, \mathrm{Ma} \mathrm{C}$, Sun $\mathrm{H}$, et al. Metabolism: a novel shared link between diabetes mellitus and Alzheimer's disease. J Diabetes Res. 2020; 2020: 4981814, doi: 10.1155/2020/4981814, indexed in Pubmed: 32083135.

8. Nguyen TT, Ta QT, Nguyen TK, et al. Type 3 diabetes and its role implications in Alzheimer's disease. Int J Mol Sci. 2020; 21(9), doi: 10.3390/ijms21093165, indexed in Pubmed: 32365816.

9. Neth BJ, Craft S. Insulin resistance and Alzheimer's disease: bioenergetic linkages. Front Aging Neurosci. 2017; 9: 345, doi: 10.3389/ fnagi.2017.00345, indexed in Pubmed: 29163128.

10. Weller J, Budson A. Current understanding of Alzheimer's disease diagnosis and treatment. F1000Res. 2018; 7, doi: 10.12688/ f1000research.14506.1, indexed in Pubmed: 30135715.

11. Sokołowska N, Sokołowski R, Oleksy E, et al. Usefulness of the Polish versions of the Montreal Cognitive Assessment 7.2 and the Mini-Mental State Examination as screening instruments for the detection of mild neurocognitive disorder. Neurol Neurochir Pol. 2020; 54(5): 440-448, doi: 10.5603/PJNNS.a2020.0064, indexed in Pubmed: 32808669.

12. Barc K, Kuźma-Kozakiewicz M. Positron emission tomography neuroimaging in neurodegenerative diseases: Alzheimer's disease,
Parkinson's disease, and amyotrophic lateral sclerosis. Neurol Neurochir Pol. 2019; 53(2): 99-112, doi: 10.5603/PJNNS.a2019.0013, indexed in Pubmed: 30855701.

13. De Sousa RA, Harmer AR, Freitas DA, et al. An update on potential links between type 2 diabetes mellitus and Alzheimer's disease. Mol Biol Rep. 2020; 47(8): 6347-6356, doi: 10.1007/s11033-02005693-z, indexed in Pubmed: 32740795.

14. Knopman DS, Jack CR, Wiste HJ, et al. 18F-fluorodeoxyglucose positron emission tomography, aging, and apolipoprotein $\mathrm{E}$ genotype in cognitively normal persons. Neurobiol Aging. 2014; 35(9): 2096-2106, doi: 10.1016/j.neurobiolaging.2014.03.006, indexed in Pubmed: 24702820.

15. Monte Sd, Wands J. Alzheimer's Disease is type 3 diabetes-evidence reviewed. Journal of Diabetes Science and Technology. 2008; 2(6): 1101-1113, doi: 10.1177/193229680800200619.

16. Meng L, Li XY, Shen L, et al. Type 2 diabetes mellitus drugs for alzheimer's disease: current evidence and therapeutic opportunities. Trends Mol Med. 2020; 26(6): 597-614, doi: 10.1016/j.molmed.2020.02.002, indexed in Pubmed: 32470386.

17. Van Dyken P, Lacoste B. Impact of metabolic syndrome on Neuroinflammation and the blood-brain barrier. Front Neurosci. 2018; 12: 930, doi: 10.3389/fnins.2018.00930, indexed in Pubmed: 30618559.

18. Kellar D, Craft S. Brain insulin resistance in Alzheimer's disease and related disorders: mechanisms and therapeutic approaches. Lancet Neurol. 2020; 19(9): 758-766, doi: 10.1016/S1474-4422(20)302313, indexed in Pubmed: 32730766.

19. Arnold SE, Arvanitakis Z, Macauley-Rambach SL, et al. Brain insulin resistance in type 2 diabetes and Alzheimer disease: concepts and conundrums. Nat Rev Neurol. 2018; 14(3): 168-181, doi: 10.1038/ nrneurol.2017.185, indexed in Pubmed: 29377010.

20. Gabbouj S, Ryhänen S, Marttinen M, et al. Altered Insulin Signaling in Alzheimer's Disease Brain - Special Emphasis on PI3K-Akt Pathway. Front Neurosci. 2019; 13: 629, doi: 10.3389/fnins.2019.00629, indexed in Pubmed: 31275108.

21. de la Monte SM, Wands JR. Alzheimer's disease is type 3 diabetes-evidence reviewed. J Diabetes Sci Technol. 2008; 2(6): 1101-1113, doi: 10.1177/193229680800200619, indexed in Pubmed: 19885299.

22. Sims-Robinson C, Kim B, Rosko A, et al. How does diabetes accelerate Alzheimer disease pathology? Nat Rev Neurol. 2010; 6(10): 551-559, doi: 10.1038/nrneurol.2010.130, indexed in Pubmed: 20842183.

23. Banks WA, Owen JB, Erickson MA. Insulin in the brain: there and back again. Pharmacol Ther. 2012; 136(1): 82-93, doi: 10.1016/j. pharmthera.2012.07.006, indexed in Pubmed: 22820012.

24. Rhea EM, Banks WA. Role of the blood-brain barrier in central nervous system insulin resistance. Front Neurosci. 2019; 13: 521, doi: 10.3389/fnins.2019.00521, indexed in Pubmed: 31213970.

25. Kleinridders A, Ferris HA, Cai W, et al. Insulin action in brain regulates systemic metabolism and brain function. Diabetes. 2014; 63(7): 2232-2243, doi: 10.2337/db14-0568, indexed in Pubmed: 24931034.

26. Ahn KC, Learman CR, Baker GB, et al. Regulation of diabetes: a therapeutic strategy for Alzheimer's disease? J Korean Med Sci. 2019; 34(46): e297, doi: 10.3346/jkms.2019.34.e297, indexed in Pubmed: 31779058.

27. Frazier $\mathrm{HN}$, Ghoweri AO, Anderson $\mathrm{KL}$, et al. Broadening the definition of brain insulin resistance in aging and Alzheimer's disease. Exp Neurol. 2019; 313: 79-87, doi: 10.1016/j.expneurol.2018.12.007, indexed in Pubmed: 30576640. 
28. Zilliox LA, Chadrasekaran K, Kwan JY, et al. Diabetes and cognitive impairment. Curr Diab Rep. 2016; 16(9): 87, doi: 10.1007/s11892016-0775-x, indexed in Pubmed: 27491830.

29. Rankin CA, Sun Q, Gamblin TC. Tau phosphorylation by GSK-3beta promotes tangle-like filament morphology. Mol Neurodegener. 2007; 2: 12, doi: 10.1186/1750-1326-2-12, indexed in Pubmed: 17598919.

30. Haque R, Nazir A. Insulin-degrading enzyme: a link between Alzheimer's and type 2 diabetes mellitus. CNS Neurol Disord Drug Targets. 2014; 13(2): 259-264, doi: 10.2174/18715273113126660139, indexed in Pubmed: 24059320.

31. Zhao L, Teter B, Morihara T, et al. Insulin-degrading enzyme as a downstream target of insulin receptor signaling cascade: implications for Alzheimer's disease intervention. J Neurosci. 2004; 24(49): 11120-11126, doi: 10.1523/JNEUROSCI.2860-04.2004, indexed in Pubmed: 15590928.

32. Tundo GR, Sbardella D, Ciaccio C, et al. Multiple functions of insulin-degrading enzyme: a metabolic crosslight? Crit Rev Biochem Mol Biol. 2017; 52(5): 554-582, doi: 10.1080/10409238.2017.1337707, indexed in Pubmed: 28635330.

33. Madhusudhanan J, Suresh G, Devanathan V. Neurodegeneration in type 2 diabetes: Alzheimer's as a case study. Brain Behav. 2020; 10(5): e01577, doi: 10.1002/brb3.1577, indexed in Pubmed: 32170854.

34. Mietlicki-Baase EG. Amylin-mediated control of glycemia, energy balance, and cognition. Physiol Behav. 2016; 162: 130-140, doi: 10.1016/j.physbeh.2016.02.034, indexed in Pubmed: 26922873.

35. Brito-Moreira J, Lourenco MV, Oliveira MM, et al. Interaction of amyloid- $\beta$ ( $A \beta$ ) oligomers with neurexin $2 \alpha$ and neuroligin 1 mediates synapse damage and memory loss in mice. J Biol Chem. 2017; 292(18): 7327-7337, doi: 10.1074/jbc.M116.761189, indexed in Pubmed: 28283575.

36. Lutz TA, Meyer U. Amylin at the interface between metabolic and neurodegenerative disorders. Front Neurosci. 2015; 9: 216, doi: 10.3389/fnins.2015.00216, indexed in Pubmed: 26136651.

37. Stanciu GD, Bild V, Ababei DC, et al. Link between diabetes and Alzheimer's disease due to the shared amyloid aggregation and deposition involving both neurodegenerative changes and neurovascular damages. J Clin Med. 2020; 9(6), doi: 10.3390/jcm9061713, indexed in Pubmed: 32503113.

38. Grizzanti J, Corrigan R, Servizi S, et al. Neuroprotective effects of amylin analogues on Alzheimer's disease pathogenesis and cognition. J Alzheimers Dis. 2018; 66(1): 11-23, doi: 10.3233/JAD-180433, indexed in Pubmed: 30282360.

39. Martinez-Valbuena I, Valenti-Azcarate R, Amat-Villegas I, et al. Amylin as a potential link between type 2 diabetes and alzheimer disease. Ann Neurol. 2019; 86(4): 539-551, doi: 10.1002/ana.25570, indexed in Pubmed: 31376172.

40. Miklossy J, Qing H, Radenovic A, et al. Beta amyloid and hyperphosphorylated tau deposits in the pancreas in type 2 diabetes. Neurobiol Aging. 2010; 31(9): 1503-1515, doi: 10.1016/j.neurobiolaging.2008.08.019, indexed in Pubmed: 18950899.

41. Despa F, Goldstein LB, Biessels GJ. Amylin as a potential link between type 2 diabetes and Alzheimer disease. Ann Neurol. 2020; 87(3): 486, doi: 10.1002/ana.25668, indexed in Pubmed: 31916276.

42. Kim N, Yoo JC, Han JY, et al. Human nuclear clusterin mediates apoptosis by interacting with $\mathrm{Bcl}-\mathrm{XL}$ through $\mathrm{C}$-terminal coiled coil domain. J Cell Physiol. 2012; 227(3): 1157-1167, doi: 10.1002/jcp.22836, indexed in Pubmed: 21567405.
43. Ha J, Moon MK, Kim H, et al. Plasma clusterin as a potential link between diabetes and Alzheimer disease. J Clin Endocrinol Metab. 2020; 105(9), doi: 10.1210/clinem/dgaa378, indexed in Pubmed: 32561922.

44. Wang W, Zhao F, Ma X, et al. Mitochondria dysfunction in the pathogenesis of Alzheimer's disease: recent advances. Mol Neurodegener. 2020; 15(1): 30, doi: 10.1186/s13024-020-00376-6, indexed in Pubmed: 32471464.

45. Wijesekara N, Gonçalves RA, De Felice FG, et al. Impaired peripheral glucose homeostasis and Alzheimer's disease. Neuropharmacology. 2018; 136(Pt B): 172-181, doi: 10.1016/j.neuropharm.2017.11.027, indexed in Pubmed: 29169962.

46. Rigotto G, Basso E. Mitochondrial dysfunctions: a thread sewing together Alzheimer's disease, diabetes, and obesity. Oxid Med Cell Longev. 2019; 2019: 7210892, doi: 10.1155/2019/7210892, indexed in Pubmed: 31316720.

47. Wang $\mathrm{CH}$, Wei YH. Role of mitochondrial dysfunction and dysregulation of Ca homeostasis in the pathophysiology of insulin resistance and type 2 diabetes. J Biomed Sci. 2017; 24(1): 70, doi: 10.1186/s12929017-0375-3, indexed in Pubmed: 28882140.

48. Karmi A, lozzo P, Viljanen A, et al. Increased brain fatty acid uptake in metabolic syndrome. Diabetes. 2010; 59(9): 2171-2177, doi: 10.2337/db09-0138, indexed in Pubmed: 20566663.

49. Gupta S, Knight AG, Gupta S, et al. Saturated long-chain fatty acids activate inflammatory signaling in astrocytes. J Neurochem. 2012; 120(6): 1060-1071, doi: 10.1111/j.1471-4159.2012.07660.x, indexed in Pubmed: 22248073.

50. Pugazhenthi S, Qin L, Reddy PH. Common neurodegenerative pathways in obesity, diabetes, and Alzheimer's disease. Biochim Biophys Acta Mol Basis Dis. 2017; 1863(5): 1037-1045, doi: 10.1016/j. bbadis.2016.04.017, indexed in Pubmed: 27156888.

51. Zhang R, Miller RG, Madison C, et al. Systemic immune system alterations in early stages of Alzheimer's disease. J Neuroimmunol. 2013; 256(1-2): 38-42, doi: 10.1016/j.jneuroim.2013.01.002, indexed in Pubmed: 23380586.

52. Ferreira ST, Clarke JR, Bomfim TR, et al. Inflammation, defective insulin signaling, and neuronal dysfunction in Alzheimer's disease. Alzheimers Dement. 2014; 10(1 Suppl): S76-S83, doi: 10.1016/j. jalz.2013.12.010, indexed in Pubmed: 24529528.

53. Cummings JL, Morstorf T, Zhong K. Alzheimer's disease drug-development pipeline: few candidates, frequent failures. Alzheimers Res Ther. 2014; 6(4): 37, doi: 10.1186/alzrt269, indexed in Pubmed: 25024750.

54. Egan MF, Kost J, Voss T, et al. Randomized trial of verubecestat for prodromal Alzheimer's disease. N Engl J Med. 2019; 380(15): 1408-1420, doi: 10.1056/NEJMoa1812840, indexed in Pubmed: 30970186.

55. Egan MF, Kost J, Tariot PN, et al. Randomized trial of verubecestat for mild-to-moderate Alzheimer's disease. N Engl J Med. 2018; 378(18): 1691-1703, doi: 10.1056/NEJMoa1706441, indexed in Pubmed: 29719179.

56. Egan MF, Mukai Y, Voss T, et al. Further analyses of the safety of verubecestat in the phase $3 \mathrm{EPOCH}$ trial of mild-to-moderate Alzheimer's disease. Alzheimers Res Ther. 2019; 11(1): 68, doi: 10.1186/s13195019-0520-1, indexed in Pubmed: 31387606.

57. Linnemann C, Lang UE. Pathways connecting late-life depression and dementia. Front Pharmacol. 2020; 11: 279, doi: 10.3389/fphar.2020.00279, indexed in Pubmed: 32231570. 
58. Reger MA, Watson GS, Green PS, et al. Intranasal insulin improves cognition and modulates beta-amyloid in early AD. Neurology. 2008; 70(6): 440-448, doi: 10.1212/01.WNL.0000265401.62434.36, indexed in Pubmed: 17942819.

59. Craft S, Claxton A, Baker LD, et al. Long-acting intranasal insulin detemir improves cognition for adults with mild cognitive impairment or early-stage Alzheimer's disease dementia. J Alzheimers Dis. 2015; 44(3): 897-906, doi: 10.3233/JAD-141791, indexed in Pubmed: 25374101.

60. Craft S, Claxton A, Baker LD, et al. Effects of regular and long-acting insulin on cognition and alzheimer's disease biomarkers: a pilot clinical trial. J Alzheimers Dis. 2017; 57(4): 1325-1334, doi: 10.3233/ JAD-161256, indexed in Pubmed: 28372335.

61. Craft S, Raman R, Chow TW, et al. Safety, efficacy, and feasibility of intranasal insulin for the treatment of mild cognitive impairment and alzheimer disease dementia: a randomized clinical trial. JAMA Neurol. 2020; 77(9): 1099-1109, doi: 10.1001/jamaneurol.2020.1840, indexed in Pubmed: 32568367.

62. Chapman CD, Schiöth HB, Grillo CA, et al. Intranasal insulin in Alzheimer's disease: Food for thought. Neuropharmacology. 2018; 136(Pt B): 196-201, doi: 10.1016/j.neuropharm.2017.11.037, indexed in Pubmed: 29180222.

63. Schmid V, Kullmann S, Gfrörer W, et al. Safety of intranasal human insulin: A review. Diabetes Obes Metab. 2018; 20(7): 1563-1577, doi: 10.1111/dom.13279, indexed in Pubmed: 29508509.

64. Tumminia A, Vinciguerra F, Parisi M, et al. Type 2 diabetes mellitus and Alzheimer's disease: role of insulin signalling and therapeutic implications. Int J Mol Sci. 2018; 19(11), doi: 10.3390/ijms19113306, indexed in Pubmed: 30355995.

65. Claxton A, Baker LD, Wilkinson CW, et al. Sex and ApoE genotype differences in treatment response to two doses of intranasal insulin in adults with mild cognitive impairment or Alzheimer's disease. J Alzheimers Dis. 2013; 35(4): 789-797, doi: 10.3233/JAD-122308, indexed in Pubmed: 23507773.

66. Zhao Na, Liu CC, Van Ingelgom AJ, et al. Apolipoprotein E4 Impairs Neuronal Insulin Signaling by Trapping Insulin Receptor in the Endosomes. Neuron. 2017; 96(1): 115-129.e5, doi: 10.1016/j.neuron.2017.09.003, indexed in Pubmed: 28957663.

67. Koenig AM, Mechanic-Hamilton D, Xie SX, et al. Effects of the insulin sensitizer metformin in Alzheimer disease: pilot data from a randomized placebo-controlled crossover study. Alzheimer Dis Assoc Disord. 2017; 31(2): 107-113, doi: 10.1097/WAD.0000000000000202, indexed in Pubmed: 28538088.

68. Chiang MC, Cheng YC, Chen SJ, et al. Metformin activation of AMPK-dependent pathways is neuroprotective in human neural stem cells against Amyloid-beta-induced mitochondrial dysfunction. Exp Cell Res. 2016; 347(2): 322-331, doi: 10.1016/j.yexcr.2016.08.013, indexed in Pubmed: 27554603.

69. Luchsinger JA, Perez T, Chang H, et al. Metformin in amnestic mild cognitive impairment: results of a pilot randomized placebo controlled clinical trial. J Alzheimers Dis. 2016; 51(2): 501-514, doi: 10.3233/ JAD-150493, indexed in Pubmed: 26890736.

70. Herath PM, Cherbuin N, Eramudugolla R, et al. The effect of diabetes medication on cognitive function: evidence from the PATH through life study. Biomed Res Int. 2016; 2016: 7208429, doi: 10.1155/2016/7208429, indexed in Pubmed: 27195294.

71. Moore EM, Mander AG, Ames D, et al. AlBL Investigators. Increased risk of cognitive impairment in patients with diabetes is associated with metformin. Diabetes Care. 2013; 36(10): 2981-2987, doi: 10.2337/dc13-0229, indexed in Pubmed: 24009301.
72. Imfeld P, Bodmer M, Jick SS, et al. Metformin, other antidiabetic drugs, and risk of Alzheimer's disease: a population-based case-control study. J Am Geriatr Soc. 2012; 60(5): 916-921, doi: 10.1111/j.1532-5415.2012.03916.x, indexed in Pubmed: 22458300.

73. Hamilton A, Hölscher C. Receptors for the incretin glucagon-like peptide-1 are expressed on neurons in the central nervous system. Neuroreport. 2009; 20(13): 1161-1166, doi: 10.1097/ WNR.0b013e32832fbf14, indexed in Pubmed: 19617854.

74. During MJ, Cao L, Zuzga DS, et al. Glucagon-like peptide-1 receptor is involved in learning and neuroprotection. Nat Med. 2003; 9(9): 1173-1179, doi: 10.1038/nm919, indexed in Pubmed: 12925848.

75. Gejl M, Gjedde A, Egefjord L, et al. In alzheimer's disease, 6-month treatment with GLP-1 analog prevents decline of brain glucose metabolism: randomized, placebo-controlled, double-blind clinical trial. Front Aging Neurosci. 2016; 8: 108, doi: 10.3389/fnagi.2016.00108, indexed in Pubmed: 27252647.

76. Batista AF, Forny-Germano L, Clarke JR, et al. The diabetes drug liraglutide reverses cognitive impairment in mice and attenuates insulin receptor and synaptic pathology in a non-human primate model of Alzheimer's disease. J Pathol. 2018; 245(1): 85-100, doi: 10.1002/ path.5056, indexed in Pubmed: 29435980.

77. Zhang Y, Xie JZ, Xu XY, et al. Liraglutide ameliorates hyperhomocysteinemia-induced Alzheimer-like pathology and memory deficits in rats via multi-molecular targeting. Neurosci Bull. 2019; 35(4): 724-734, doi: 10.1007/s12264-018-00336-7, indexed in Pubmed: 30632006.

78. McClean PL, Parthsarathy V, Faivre E, et al. The diabetes drug liraglutide prevents degenerative processes in a mouse model of Alzheimer's disease. J Neurosci. 2011; 31(17): 6587-6594, doi: 10.1523/JNEUROSCI.0529-11.2011, indexed in Pubmed: 21525299.

79. McClean PL, Parthsarathy V, Faivre E, et al. The novel GLP-1 analogue liraglutide has neuroprotective properties in a mouse model of Alzheimer's disease. Regulatory Peptides. 2010; 164(1): 40, doi: 10.1016/j.regpep.2010.07.102.

80. Hansen HH, Fabricius K, Barkholt P, et al. The GLP-1 receptor agonist liraglutide improves memory function and increases hippocampal CA1 neuronal numbers in a senescence-accelerated mouse model of Alzheimer's disease. J Alzheimers Dis. 2015; 46(4): 877-888, doi: 10.3233/JAD-143090, indexed in Pubmed: 25869785.

81. Watson KT, Wroolie TE, Tong G, et al. Neural correlates of liraglutide effects in persons at risk for Alzheimer's disease. Behav Brain Res. 2019; 356: 271-278, doi: 10.1016/j.bbr.2018.08.006, indexed in Pubmed: 30099030.

82. Femminella GD, Frangou E, Love SB, et al. Evaluating the effects of the novel GLP-1 analogue liraglutide in Alzheimer's disease: study protocol for a randomised controlled trial (ELAD study). Trials. 2019; 20(1): 191, doi: 10.1186/s13063-019-3259-x, indexed in Pubmed: 30944040.

83. Kosaraju J, Holsinger RM, Guo L, et al. Linagliptin, a dipeptidyl peptidase-4 inhibitor, mitigates cognitive deficits and pathology in the 3xTg-AD mouse model of Alzheimer's disease. Mol Neurobiol. 2017; 54(8): 6074-6084, doi: 10.1007/s12035-016-0125-7, indexed in Pubmed: 27699599.

84. Kornelius E, Lin CL, Chang HH, et al. DPP-4 inhibitor linagliptin attenuates AB-induced cytotoxicity through activation of AMPK in neuronal cells. CNS Neurosci Ther. 2015; 21(7): 549-557, doi: 10.1111/ cns.12404, indexed in Pubmed: 26010513.

85. Isik AT, Soysal P, Yay A, et al. The effects of sitagliptin, a DPP-4 inhibitor, on cognitive functions in elderly diabetic patients with or without Alzheimer's disease. Diabetes Res Clin Pract. 2017; 123: 192-198, doi: 10.1016/j.diabres.2016.12.010, indexed in Pubmed: 28056430. 
86. Landreth G, Jiang Q, Mandrekar S, et al. PPARgamma agonists as therapeutics for the treatment of Alzheimer's disease. Neurotherapeutics. 2008; 5(3): 481-489, doi: 10.1016/j.nurt.2008.05.003, indexed in Pubmed: 18625459.

87. Muñoz-Jiménez M, Zaarkti A, García-Arnés JA, et al. Antidiabetic drugs in Alzheimer's disease and mild cognitive impairment: A systematic review. Dement Geriatr Cogn Disord. 2020; 49(5): 423-434, doi: 10.1159/000510677, indexed in Pubmed: 33080602.

88. Quan Q, Qian Y, Li Xi, et al. Pioglitazone reduces $\beta$ amyloid levels inhibition of PPARy phosphorylation in a neuronal model of Alzheimer's disease. Front Aging Neurosci. 2019; 11: 178, doi: 10.3389/fnagi.2019.00178, indexed in Pubmed: 31379559.

89. Hanyu $\mathrm{H}$, Sato $\mathrm{T}$, Sakurai $\mathrm{H}$, et al. The role of tumor necrosis factor-alpha in cognitive improvement after peroxisome proliferator-activator receptor gamma agonist pioglitazone treatment in Alzheimer's disease. J Am Geriatr Soc. 2010; 58(5): 1000-1001, doi: 10.1111/j.1532-5415.2010.02841.x, indexed in Pubmed: 20722838.

90. Fernandez-Martos CM, Atkinson RAK, Chuah MI, et al. Combination treatment with leptin and pioglitazone in a mouse model of Alzheimer's disease. Alzheimers Dement (N Y). 2017; 3(1): 92-106, doi: 10.1016/j.trci.2016.11.002, indexed in Pubmed: 29067321.

91. Knodt AR, Burke JR, Welsh-Bohmer KA, et al. Effects of pioglitazone on mnemonic hippocampal function: A blood oxygen level-dependent functional magnetic resonance imaging study in elderly adults. Alzheimers Dement (N Y). 2019; 5: 254-263, doi: 10.1016/j. trci.2019.05.004, indexed in Pubmed: 31304231.

92. Hanyu H, Sato T, Kiuchi A, et al. Pioglitazone improved cognition in a pilot study on patients with Alzheimer's disease and mild cognitive impairment with diabetes mellitus. J Am Geriatr Soc. 2009; 57(1): 177-179, doi: 10.1111/j.1532-5415.2009.02067.x, indexed in Pubmed: 19170800.

93. Sato T, Hanyu H, Hirao K, et al. Efficacy of PPAR-y agonist pioglitazone in mild Alzheimer disease. Neurobiol Aging. 2011; 32(9): 1626-1633, doi: 10.1016/j.neurobiolaging.2009.10.009, indexed in Pubmed: 19923038.
94. Li H, Wu J, Zhu L, et al. Insulin degrading enzyme contributes to the pathology in a mixed model of Type 2 diabetes and Alzheimer's disease: possible mechanisms of IDE in T2D and AD. Biosci Rep. 2018; 38(1), doi: 10.1042/BSR20170862, indexed in Pubmed: 29222348.

95. Xu S, Guan Q, Wang C, et al. Rosiglitazone prevents the memory deficits induced by amyloid-beta oligomers via inhibition of inflammatory responses. Neurosci Lett. 2014; 578: 7-11, doi: 10.1016/j. neulet.2014.06.010, indexed in Pubmed: 24933538.

96. Risner ME, Saunders AM, Altman JFB, et al. Rosiglitazone in Alzheimer's Disease Study Group. Efficacy of rosiglitazone in a genetically defined population with mild-to-moderate Alzheimer's disease. Pharmacogenomics J. 2006; 6(4): 246-254, doi: 10.1038/ sj.tpj.6500369, indexed in Pubmed: 16446752.

97. Gold M, Alderton C, Zvartau-Hind M, et al. Rosiglitazone monotherapy in mild-to-moderate Alzheimer's disease: results from a randomized, double-blind, placebo-controlled phase III study. Dement Geriatr Cogn Disord. 2010; 30(2): 131-146, doi: 10.1159/000318845, indexed in Pubmed: 20733306.

98. Grizzanti J, Corrigan R, Casadesus G. Neuroprotective effects of amylin analogues on Alzheimer's disease pathogenesis and cognition. J Alzheimers Dis. 2018; 66(1): 11-23, doi: 10.3233/JAD-180433, indexed in Pubmed: 30282360.

99. Zhu H, Wang $X$, Wallack $\mathrm{M}$, et al. Intraperitoneal injection of the pancreatic peptide amylin potently reduces behavioral impairment and brain amyloid pathology in murine models of Alzheimer's disease. Mol Psychiatry. 2015; 20(2): 252-262, doi: 10.1038/mp.2014.17, indexed in Pubmed: 24614496.

100. Soudy R, Patel A, Fu W, et al. Cyclic AC253, a novel amylin receptor antagonist, improves cognitive deficits in a mouse model of Alzheimer's disease. Alzheimers Dement (N Y). 2017; 3(1): 44-56, doi: 10.1016/j.trci.2016.11.005, indexed in Pubmed: 29067318. 